Fourth International Conference on Sustainable Construction Materials and Technologies http://www.claisse.info/Proceedings.htm

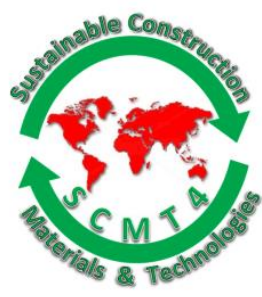

SCMT4

Las Vegas, USA, August 7-11, 2016

\title{
Towards The Corrosion Modelling of Cracked Reinforced SHCC in Accelerated Chloride Exposure
}

\author{
Suvash Chandra Paul ${ }^{1 \mathrm{a}, 2}$, and Gideon P.A.G van Zijl ${ }^{1 \mathrm{~b}}$ \\ ${ }^{1}$ Department of Civil Engineering; Stellenbosch University; Private Bag X1, Matieland, Stellenbosch, \\ South Africa. ${ }^{1 b}$ Email: 〈gvanzijl@sun.ac.za〉. \\ ${ }^{2}$ Singapore Center for 3D Printing; School of Mechanical and Aerospace Engineering; Nanyang \\ Technological University; Singapore. ${ }^{1 a, 2}$ Email: 〈suvashpl@ntu.edu.sg〉.
}

\begin{abstract}
Corrosion of steel bars in concrete is usually a slow electrochemical process, which may need a long time before damage becomes visible in reinforced concrete (RC). Corrosion modelling is essential for the design of structures or structural elements for a particular life span or in deciding whether a RC structure needs repair or rehabilitation work to reach or extend its design service life. This paper presents a corrosion model for cracked reinforced strain-hardening cement-based composite (R/SHCC) under chloride exposure. The model incorporates crack width, crack spacing, free chloride content and cover depth. It is shown to capture corrosion test results of cracked R/SHCC with reasonable accuracy.
\end{abstract}

\section{INTRODUCTION}

The main features of strain hardening cement-based composite (SHCC) are the formation of multiple fine cracks and increased tensile resistance whilst the next cracks appear (Li et al. 1993). This can be achieved with relatively low volumes of discontinuous, short fibres, and usual mixing and casting procedures. Applications of this class of material include bonded overlay constructions or repairs like composite bridge decks and dam faces, and as energy dissipating structural elements in seismic regions, for instance coupling beams and floors in tall buildings. In general, the finely cracked SHCC has been shown to reduce ingress rates, which fact holds potential for reducing corrosion rates in reinforced SHCC (R/SHCC) structures and thus an extended service life (Sahmaran et al. 2008, Kobayashi et al. 2010).

A vast pool of research data on reinforced concrete (RC) corrosion has been developed over the past several decades, including the reduced density, or increased volume of various corrosion products including amongst others $\mathrm{FeO}, \mathrm{Fe}_{3} \mathrm{O}_{4}$ and $\mathrm{Fe}(\mathrm{OH})_{3} 3 \mathrm{H}_{2} \mathrm{O}$ [Liu \& Weyers 1998; Andrade et al. 1993; Coronelli 2002; Colotti \& Spadea 2004; Chen \& Mahadevan 2007]. However, the corrosion data for $\mathrm{R} / \mathrm{SHCC}$ is limited. No corrosion model for this new type of construction material exists. The existing models for corrosion in RC are open to criticism due to the fact that they sometimes over estimate or underestimate actual corrosion [Otieno et al. 2010]. Also, most prediction models for chloride-induced corrosion in RC generally assume uncracked concrete, while design standards generally allow, but limit crack widths in service conditions. These models typically enable estimation of the time for sufficient concentration levels of chloride to reach reinforcing steel in RC to cause corrosion initiation [Li \& Yang 2011]. 
The time to corrosion-induced cracking is determined by considering the time-dependent pressure buildup by these corrosion products in the surrounding concrete, including refined consideration for impregnation of the porous interfacial zone surrounding the steel. Another category of models could be considered for corrosion in cracked RC, whether by mechanical load, shrinkage or corrosion itself as described above. This is the most complicated category, influenced by various mechanisms and probably the reason why limited modelling attempts have been reported [Mohammed et al. 2001; Granju \& Balouch 2005]. It is generally believed that the probability of corrosion is increased with increased crack width [Vidal et al. 2004], which is the background of crack width limitation by design standards for durability of RC. However, light was shed on the importance of crack spacing by Arya \& Darko (1996) for corrosion rate in RC.

For this second category of corrosion models, i.e. to capture chloride-induced corrosion rate in cracked $\mathrm{RC}$ or $\mathrm{R} / \mathrm{SHCC}$, there is no existing evidence that corrosion rate, subsequent to initiation, is dependent on chloride content. For corrosion initiation in concrete a threshold level of free chloride at the steel surface is required. However, based on several factors, a range of threshold limit values have been reported by various authors, e.g. Mohammed et al. (2001), Alonso et al. (2000). Since the SHCC matrix composition differs from that of traditional concrete types, the threshold chloride level in SHCC may also differ. Nevertheless, the published data on chloride content and profiles in SHCC is limited [Wittmann et al. 2011; Kojima et al. 2014]. This motivates the investigation of crack width, spacing and chloride content in R/SHCC reported here, and inclusion of these governing parameters in a corrosion model. Based on parametric studies on cover depth, crack spacing, crack width, and free chloride at the steel surface, empirical relations are proposed for corrosion modelling in cracked R/SHCC specimens. In this paper, a Coulostatic method is used to measure the corrosion rate in the steel bar [Glass 1995; Gonzalez et al. 2001; Andrade \& Alonso 2004; Paul \& van Zijl 2014]. Accelerated chloride-induced corrosion was performed by cyclic exposure to chloride followed by drying periods, in regular weekly cycles, arguably representative of a large portion of infrastructural deterioration exposure situations in coastal regions or subject to the use of salt-based de-icing practice. The specimens reported here were exposed to $3.5 \%$ $\mathrm{NaCl}$ solution in cycles of 3 days wetting and 4 days drying, up to total durations of 6 to 13 months.

\section{EXPERIMENTAL INVESTIGATION}

The SHCC contained finely grained sand (maximum particle size up to $0.3 \mathrm{~mm}$ with fineness modulus 1.9). Polyvinyl alcohol (PVA) fibres of $12 \mathrm{~mm}$ length and $0.04 \mathrm{~mm}$ diameter were used. Specimens for characterization included $100 \mathrm{~mm}$ cubes for compressive strength, $100 \mathrm{~mm}$ diameter by $200 \mathrm{~mm}$ high cylinders for E-modulus, beams for flexural strength and small dumbbell shaped specimens with cross section of $16 \mathrm{~mm} \times 30 \mathrm{~mm}$ for uniaxial tension. The cubes were tested at the age of 28 days while reinforced beams and unreinforced dumbbell specimens were tested at 14 days. Two days after mixing, all specimens were stripped from the moulds, kept in water at $21 \pm 2^{\circ} \mathrm{C}$ for 7 days, after which all the specimens were stored at ambient laboratory temperature $21 \pm 2^{\circ} \mathrm{C}$ and relative humidity $60 \pm 5 \%$ until the testing date.

Specimen preparation for corrosion testing of R/SHCC. For R/SHCC corrosion testing of FS31 and FS322, $80 \mathrm{~mm}$ x $100 \mathrm{~mm}$ x $490 \mathrm{~mm}$ beams were used. A $10 \mathrm{~mm}$ diameter steel bar (Y10) of $500 \mathrm{~mm}$ length was placed inside the beams at three different cover depths. In case of FS31, 18 specimens were prepared, with parameters the cover depth $(15,25,35 \mathrm{~mm})$ and deflection level $(5$ and $7 \mathrm{~mm})$ in threepoint bending pre-cracking. After unloading, all FS31 specimens were placed in specially prepared steel frames shown in figure 1a, in which the 5 and $7 \mathrm{~mm}$ central deflection respectively was re-applied by tightening the bolts at the specimen ends. These levels of deformation were maintained in the frames. At this level several cracks were found on the bottom, tensile surface of each specimen (see figure 1b). 
Table 1. SHCC mix proportions

\begin{tabular}{|c|c|c|c|c|c|c|}
\hline Type & Id & Cement & Water & Fly-ash & Sand & Fibre (\%) \\
\hline SHCC & FS31 / FS32 & CEM I 52.5: 1.0 & 1.0 & 1.72 & 1.41 & 2.0 \\
\hline
\end{tabular}

Note that superplasticizer and viscosity modifying agents were added to achieve the correct fresh properties of the SHCC.

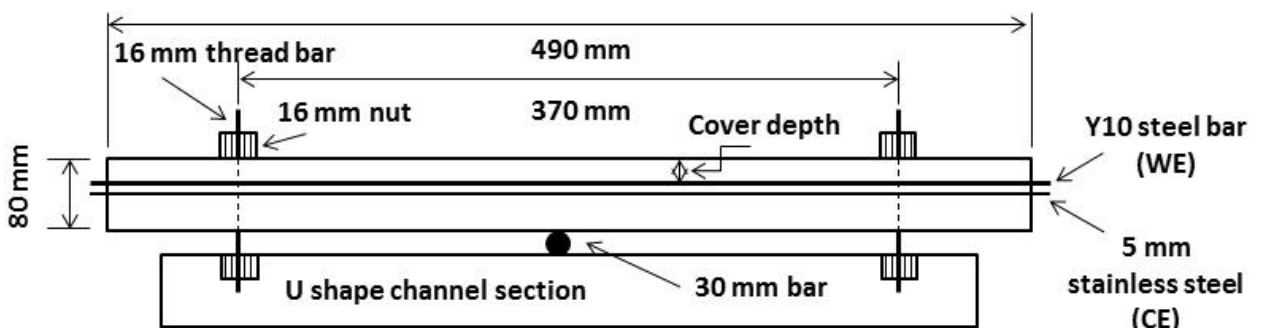

(a) R/SHCC beam under sustained load

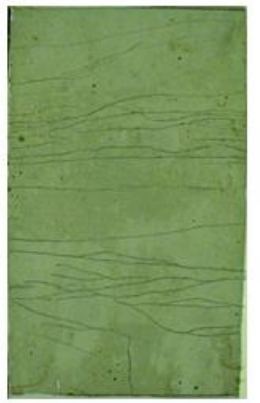

(b) Forming Cracks in FS31 specimens in flexural testing

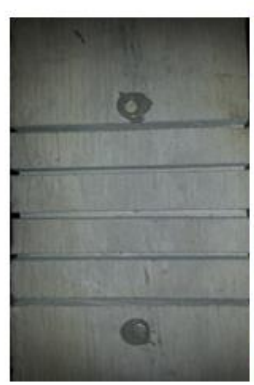

(c) FS32 specimens with N5 @ 20 mm spacing

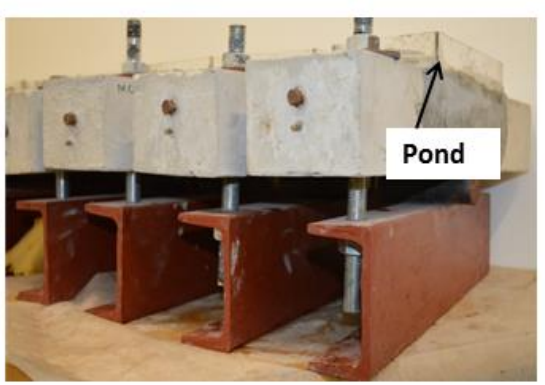

(d) Preparation of ponding specimens

\section{Figure 1. R/SHCC specimen preparation for corrosion testing.}

In total 18 FS32 specimens were prepared, each with a single Y10 bar, but in this case the parameters were 2 cover depths $(15,25 \mathrm{~mm})$ and crack spacing $(20 \mathrm{~mm}, 40 \mathrm{~mm}$, a single crack), with 3 specimens of each type. The crack spacing was enforced by notches sawn $10 \mathrm{~mm}$ deep and $3 \mathrm{~mm}$ wide in the tensile face of the specimens, with three different numbers of notches (N1, N3 at $40 \mathrm{~mm}$ spacing, and N5 at 20 mm spacing) in the central part of the specimens as shown in Fig 1c. After cutting the notches, all the specimens were placed in similar steel frames as the FS31 specimens, and cracks were formed by tightening the bolts at the frame ends. In this case the specimens were loaded up to a certain tensile surface elongation level measured over a gauge length of $100 \mathrm{~mm}$ over the notched region. For 1, 3 and 5 notches the surface elongation was $0.3 \mathrm{~mm}, 0.9 \mathrm{~mm}$ and $1.5 \mathrm{~mm}$ respectively in order to create cracks in the notches of roughly equal widths. In both FS31 and FS32 specimens, a $6 \mathrm{~mm}$ stainless steel bar was embedded as shown in figure 1a for the corrosion testing. A $200 \mathrm{~mm} \times 100 \mathrm{~mm}$ pond was built on each specimen's cracked surface (figure 1d) from non-absorbent plastic, sealed with silicon. $\mathrm{NaCl}$ aqueous solution (3.5\% by weight) was applied on the top surface for 3 days, followed by 4 days of drying, repeated for 57 weeks (FS31) and 28 weeks (FS32) respectively. The specimen sides were sealed to allow one-dimensional penetration. 


\section{Method of corrosion measurement and chloride content in R/SHCC specimens}

A Coulostatic method was followed for determining the steel corrosion rate $\left(V_{\text {corr }}\right)$. In this method the steel reinforcing bar (Y10) acts as the working electrode (WE), the stainless steel bar acts as the counter electrode (CE) and an $\mathrm{Ag} / \mathrm{AgCl}$ half-cell was used as the reference electrode. A Spider8 data logger was used while a current of $4 \mathrm{~mA}$ was applied to each specimen for a period of $5 \mathrm{mS}$ by a laboratory built current pulse generator. However, for 6 FS31 specimens with cover depth of $15 \mathrm{~mm}$ a different current of $10 \mathrm{~mA}$ for a period of $6 \mathrm{mS}$ was used. The reason was the very low perturbation when the applied current was $4 \mathrm{~mA}$ for a period of $5 \mathrm{mS}$ in these specimens. Details of the Coulostatic corrosion measuring technique were described by the several researchers [Glass 1995; Gonzalez et al. 2001; Andrade \& Alonso 2004; Paul 2015]. Finally, from the corrosion rate results, Eq. (1) was used to estimate uniformly corroded depth $\left(d_{c}\right)$ in the steel bars:

$$
d_{c}(t)=d_{c 0}+\int_{0}^{t} V_{c o r r} d t=d_{c 0}+\sum_{i=1}^{N_{t}} \frac{1}{2}\left(V_{c o r r}+V_{c o r r, i-1}\right)\left(t_{i}-t_{i-1}\right)
$$

After accelerated testing, the specimens were broken to observe actual corrosion in the steel, measure loss of rebar tensile resistance and pitting depths. In order to study the chloride penetration into the cracked specimens, more than 15 specimens from both types of R/SHCC were chosen. Drilling was performed to collect powder samples from the drilling residue. A drill with diameter of $16 \mathrm{~mm}$ was used to ensure sufficient powder per $3 \mathrm{~mm}$ layer up to $45 \mathrm{~mm}$ depth. Note that the chloride content obtained here is one dimensional (depth) and the average value of different positions at that layer depth. All the drilling positions were into cracks. X-ray fluorescence (XRF) testing was performed to determine the total chloride content. Chemical analysis (RILEM TC 178-TMC 2002) was also performed, for total and free chloride content.

\section{Method of determining mass loss, pitting depths and loss of yield force of corroded steel bars of R/SHCC}

At the end of the chloride exposure, all specimens were broken and the steel bars collected and cleaned with hydrochloric acid $(\mathrm{HCl})$ and a wire brush. The mass loss, actual pitting depths and the loss of yield force of the steel bars were determined. The corrosion mass loss and loss of yield force was determined for FS32 specimens only. A dial gauge with a resolution of $10 \mu \mathrm{m}$ was used to measure pitting depth. A Zwick Z250 materials testing machine (MTM) was used to determine the yield force (loading rate was 2 $\mathrm{mm} / \mathrm{min}$ ) of the corroded steel bars and loss of yield force was calculated by comparison with the yield force of reference steel bars.

\section{RESULTS AND DISCUSSIONS}

Small cone slump flow (170-210 mm) and air content (3\%-4.8\%) were determined. Table 2 shows the mechanical properties compressive $\left(f_{c u}\right)$, flexural $\left(f_{u, f t}\right)$ and uniaxial tensile strength $\left(f_{u, s t}\right)$.

Table 2. SHCC mechanical properties

\begin{tabular}{|c|c|c|c|c|c|c|}
\hline \multirow{2}{*}{ Id } & \multicolumn{3}{|c|}{ Strength (MPa) } & \multirow{2}{*}{$\begin{array}{c}\text { E-mod } \\
\text { (GPa) }\end{array}$} & $\begin{array}{c}\text { Ultimate flexural } \\
\text { deformation (mm) }\end{array}$ & $\begin{array}{c}\text { Ultimate tensile } \\
\text { strain (\%) }\end{array}$ \\
\cline { 2 - 4 } & $f_{c u}$ & $f_{u, f t}$ & $f_{u, s t}$ & & $3-4$ & $2-2.2$ \\
\hline FS31 \& FS32 & $23-26$ & $7-9$ & $2.2-2.8$ & $13-14$ & $3-4$ & $2-2$ \\
\hline
\end{tabular}




\section{Relation between cracks, corroded depth and chloride in R/SHCC}

The correlations between average crack widths (ACW) and crack spacing with corroded depths in R/FS31 specimens after 57 weeks of accelerated testing are shown in Figs. 2a,b. Larger corroded depths are apparent for larger average crack widths and spacing. It must be kept in mind that figure 2 does not distinguish between the different cover depths. Wider cracks, and significantly higher corroded depths were found in the specimens with $15 \mathrm{~mm}$ cover depth.
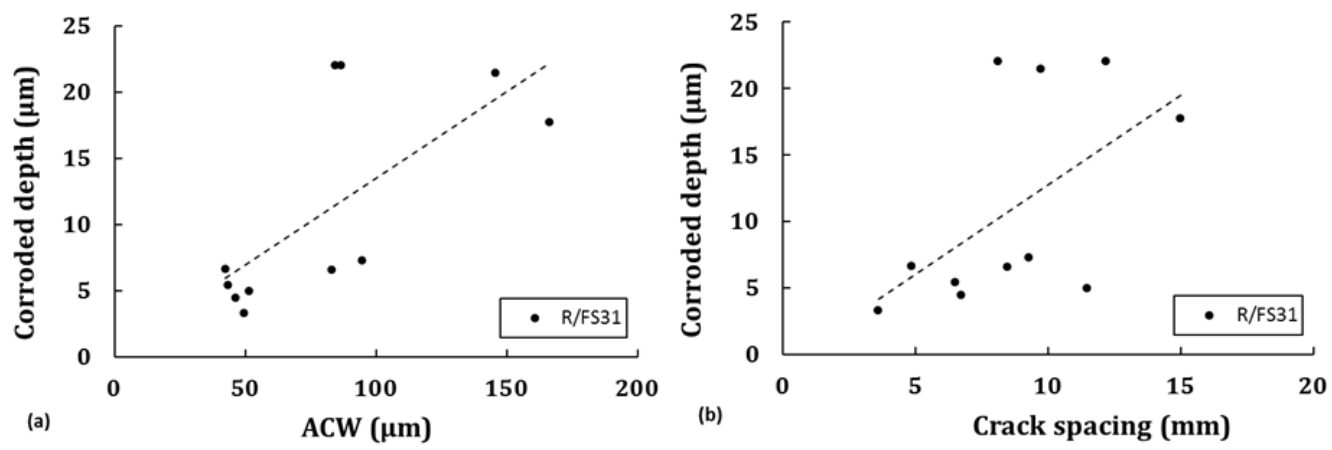

\section{Figure 2. Influence of average crack widths (ACW) and spacing on corroded depths in R/FS31 specimens after 58 weeks of the exposure period.}

The correlation between average crack width and XRF total chloride $(\mathrm{Cl})$ content is shown in figure 3 . For average crack widths below $0.06 \mathrm{~mm}$ no relationship appears to exist. However, as the crack width increase it appears that the total chloride increases. It must also be kept in mind that as the exposure time increase the influence of crack widths might diminish through gradual chloride ingress into the matrix from the crack faces subsequent to quick ingress into the cracks [Paul, 2015].

Cracks and pitting depth in R/SHCC. The average pitting depths in the individual steel bars were found to be lower for larger total crack widths in the R/FS31 specimens, as shown in figure 4a. It might be explained by the formation of micro-cell corrosion in the steel bar due to higher number of cracks and thus closer crack spacing which led to distributed corrosion. Larger pitting depths are seen for larger crack spacing in figure $4 \mathrm{~b}$. For finer crack spacing, the cathodic area reduces relative to the anodic area. Thereby, less $\mathrm{OH}^{-}$ions are available from the smaller cathodic area to react with the $\mathrm{Fe}^{+}$in the anodic area. In this case corrosion is also distributed over the length of steel bar and it is expected to have distributed pitting to smaller depth rather than concentrated, deep pitting.

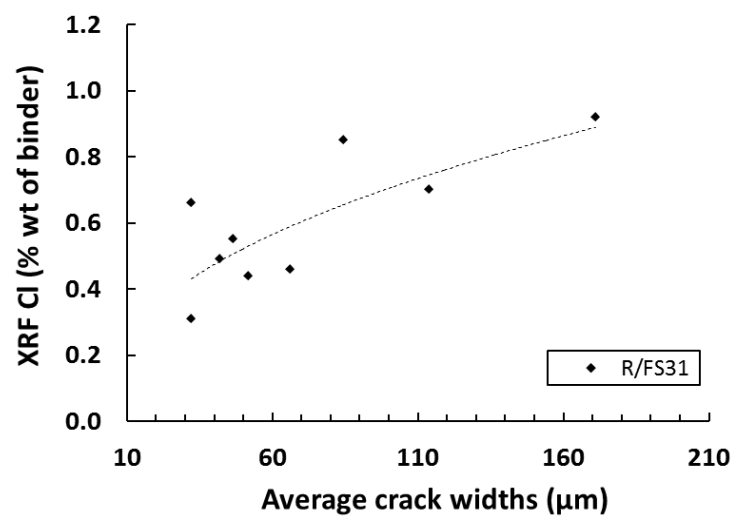

Figure 3. XRF total chloride (Cl) vs. average crack widths in R/SHCC after 57 weeks. 

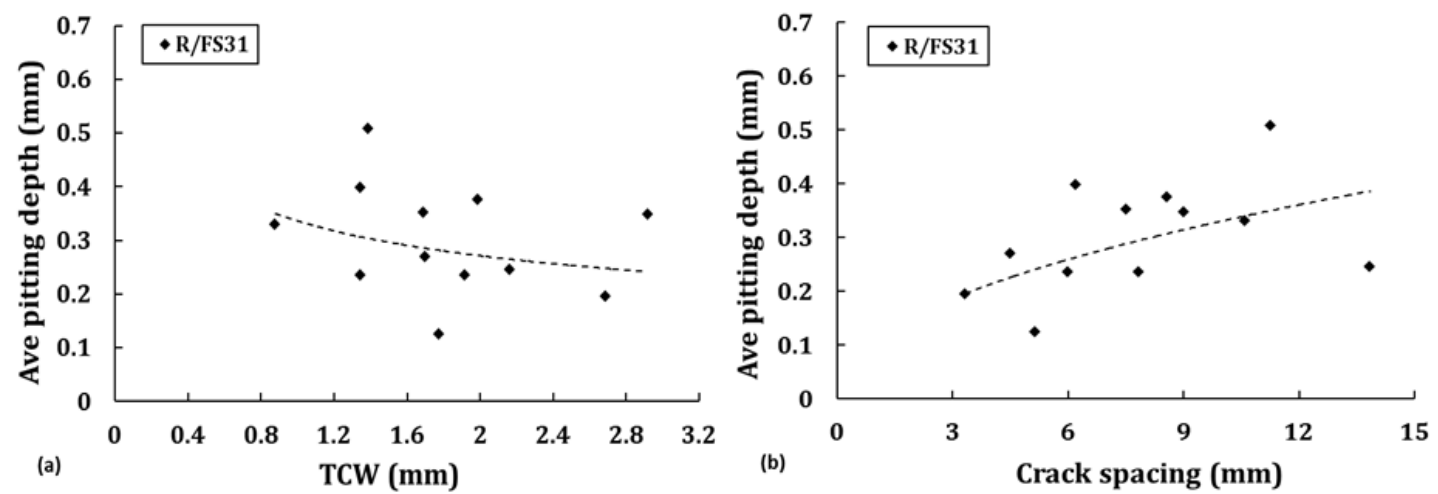

Figure 4. Pitting depths vs. total crack widths (TCW) and crack spacing in R/SHCC at the end of their exposure periods.

Total and free chloride in R/SHCC. Figures $5 \mathrm{a}$ and $\mathrm{b}$ show the total and free chloride profiles from chemical testing in R/FS31 and R/FS32. The typical trend of high chloride content at the surface, and gradual reduction with depth is clear in the figures. Figure 6 shows correlations between the corroded depths determined by the Coulostatic method (Eq. 1) and total and free chloride contents at the surface of steel bars in the different R/SHCC specimens. A better correlation is seen between corroded depth and free chloride content, suggesting that free chloride content might be more relevant for the corrosion.

Consequences of corrosion and chloride in steel bars of R/SHCC. The actual steel bar mass loss after 28 weeks of cyclic chloride exposure of R/FS32 specimens was determined by subtracting the steel bar mass from its original mass. These results are compared with the actual loss of yield resistance in figure 7. The loss of yield force increases as the mass loss in the steel bars increase. In figure 7, mass loss per unit length is shown. The solid line represents a calibrated physical relation for loss of yield resistance $\left(Y_{\text {loss }}\right)$ of a steel bar due to corrosion, expressed as follows:

$$
\begin{gathered}
Y_{\text {loss }}=\frac{1}{k} \sigma_{y} A_{r} \\
A_{r}=\frac{A_{s} m_{2}}{m_{1}}
\end{gathered}
$$

which incorporates the corrosion-induced reduction in steel bar cross-sectional area.
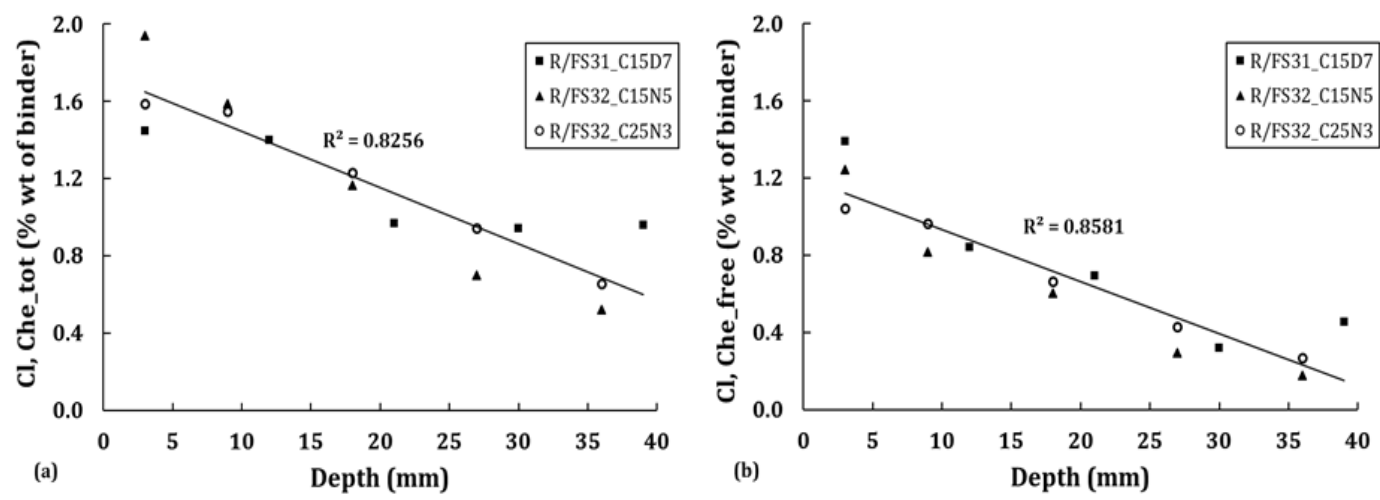

Figure 5. (a) Total and (b) free chloride (Cl) profiles in R/SHCC from chemical testing. 


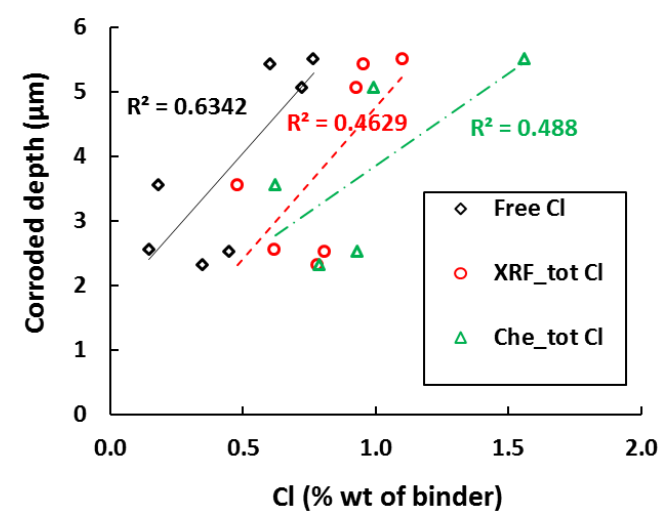

Figure 6. Total and free chloride (Cl) vs. corroded depths in R/SHCCs.

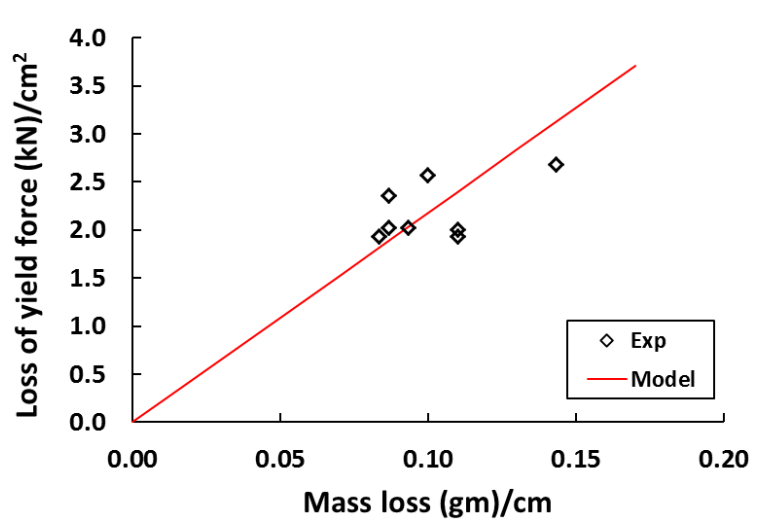

Figure 7. Relationship between loss of yield force and actual mass loss in R/FS32.

where $m_{1}=\rho_{s} A_{s}$ is the mass of steel per unit length, given that $\rho_{s}$ is the density of steel and $A_{s}$ is the cross-sectional area of steel, $m_{2}$ is the corrosion-induced mass loss per unit length, $\sigma_{y}$ is yield stress of steel and $k$ is a calibration factor which is argued to depend on the exposure duration. In this case the value of $k$ was taken as 2.80 . Eq. (3) is clearly not intended for prediction of corrosion, but merely physical confirmation of loss of resistance associated with mass loss of steel, given that the locality of corrosion damage can be determined.

\section{CORROSION MODELLING OF R/SHCC}

To date no corrosion model for cracked R/SHCC exposed to chloride has been proposed in the literature. Due to limited corrosion data on SHCC, the validation of the results is also a difficult task and more research is needed in this regard. Long term laboratory and field data are necessary to validate any corrosion model for this new material. In this section, the data sets generated in the research reported here are used to develop a model.

\section{Proposed corrosion modelling for $\mathrm{R} / \mathrm{SHCC}$}

From the relationships shown above between corrosion and crack width, crack spacing, cover depth and chloride content, the following two relations have been derived:

$d_{c}=\frac{\delta_{T} \delta_{R H} W_{c r, a v e} t^{\alpha_{t}} C l_{\text {free }}^{\alpha_{c l}}}{C^{\alpha C}} \quad$ for R/SHCC containing a single crack

$d_{c}=\frac{0.35 \delta_{T} \delta_{R H} W_{c r, a v e t^{\alpha_{t}}} C l_{f r e e}^{\alpha_{c l}} S_{c r}^{\alpha_{S}}}{C^{\alpha}}$ for R/SHCC containing multiple cracked

where $d_{c}$ is the corroded depth $(\mu \mathrm{m}), t$ is the corrosion time (year), $W_{c r, a v e}$ is the average crack width in the specimens $(\mu \mathrm{m}), C l_{\text {free }}$ is the $\%$ of free chloride at the steel surface level (\% wt of binder), $S_{c r}$ is the average crack spacing in the specimens (mm) and $C$ is the cover depth of the steel bar. $\delta_{T}$ and $\delta_{R H}$ are the factors that depend on the temperature and relative humidity $(\mathrm{RH})$ at the steel bar level. At the specimen surface temperature of $21 \pm 2^{\circ} \mathrm{C}, \delta_{T}$ can be considered to be 1 . And similarly for $55 \pm 5 \% \mathrm{RH}, \delta_{R H}$ can be considered to be 1. $\alpha_{t}, \alpha_{c l}, \alpha_{S}$ and $\alpha_{C}$ are the factors that depend on the ratio of wetting and drying periods, 
types of binder, range of maximum crack spacing and quality of cover concrete, i.e. micro-structure and tensile strength of concrete. In this research work, the value of $\alpha_{t}, \alpha_{c l}, \alpha_{S}$ and $\alpha_{C}$ were considered to be 0.68 , 0.5, 0.27 and 0.3 respectively. With these values, figure 8 shows reasonable agreement between Eq. (4) and the experimental data for single crack (notched) specimens, while in Figs. 9a\&b Eq. (5) is shown to be in agreement with corroded depths in multiple cracked R/FS32 specimens. These values may need to be re-calibrated for other SHCC types, exposure conditions, age and corrosion rate measurement techniques. In both Figs. $8 \& 9$ the data points represent Coulostatic corrosion rate measurements and application of Eq. (1).

figure 9a shows the corroded depths of R/FS32 specimens with $15 \mathrm{~mm}$ cover, and with three notches (N3) and five notches (N5) which correspond to the crack spacing of $40 \mathrm{~mm}$ and $20 \mathrm{~mm}$. The larger crack spacing of N3 specimen was found to cause higher corroded depths in the steel bar. Figure 9b shows the similar trend as in figure $9 \mathrm{a}$, now for $25 \mathrm{~mm}$ cover depth. The proposed corrosion model is valid for Coulostatic measuring method of the R/SHCC specimen in the laboratory experiments where the temperature $\left(21 \pm 2^{\circ} \mathrm{C}\right)$ and $\mathrm{RH}(55 \pm 5 \%)$ were controlled throughout the testing period. Therefore for the different temperature, $\mathrm{RH}$ and corrosion measuring method, the proposed modelling may need to be calibrated.

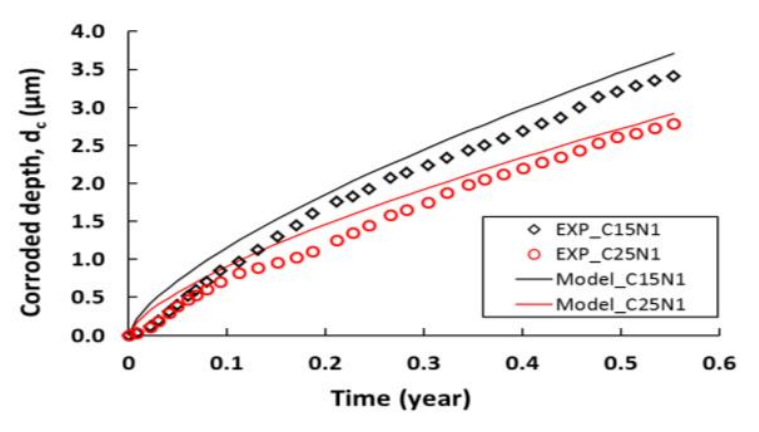

Figure 8. Corrosion modelling using Eq. (4) of R/SHCC with a single crack.
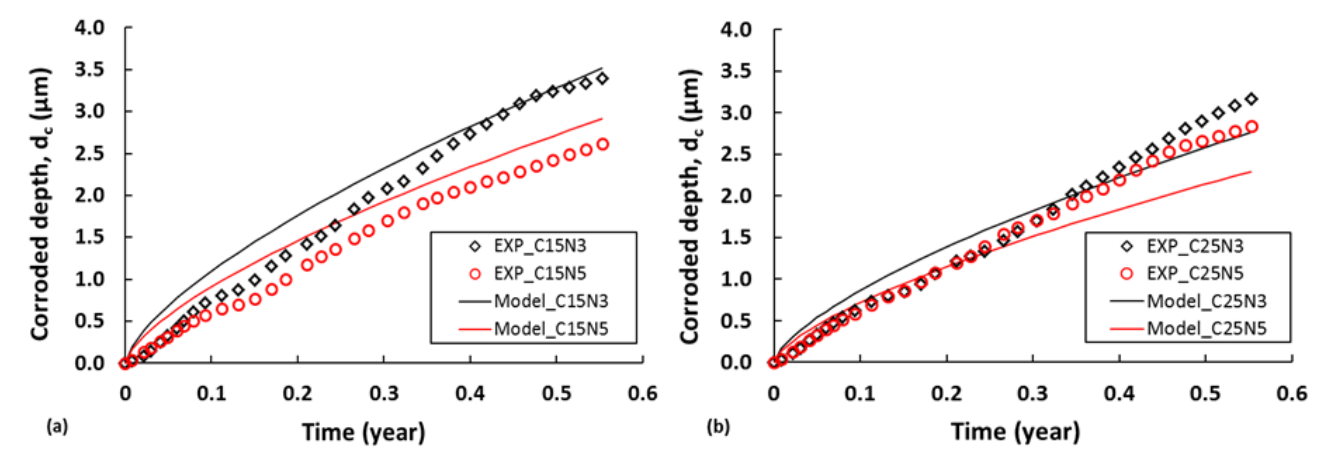

Figure 9. Corrosion modelling using Eq. (5) of R/SHCC with multiple cracks.

\section{CONCLUSION}

The chloride-induced corrosion rate in R/SHCC is related to crack width and spacing, cover depth and chloride-content. From the results reported in this paper, the following conclusions are drawn:

- The corroded depth is larger for larger crack width and spacing. 
- The amount of free chloride content at the level of the steel bar surface appears to be better correlated to actual corrosion damage than the total chloride content.

- Corrosion mass loss is related to the loss of yield resistance of steel bars.

- The experimental results of chloride-induced corrosion reported in this paper can be represented by power functions incorporating average crack width, crack spacing, free chloride content at the steel surface and the time of exposure.

\section{REFERENCES}

Alonso, C., Andrade, C., Castellote, M., and Castro, P. (2000). "Chloride threshold values to depassivate reinforcing bars embedded in a standardized OPC mortar." Cement and Concrete Research, 30:10471055.

Andrade, C., Molina, F. J., and Alonso, C. (1993). "Cover cracking as a function of rebar corrosion: part I-experiment test." Materials and Structures, 26:453-464.

Andrade, C., and Alonso, C. (2004). "Test Methods for on-site corrosion rate of steel reinforcing in concrete by means of the polarization resistance method." Materials and Structures, 37(9):623-643.

Arya, C., and Ofori-darko, F. K. (1996). "Influence of crack frequency on reinforcement corrosion in concrete." Cement and Concrete Research, 26(3):345-353.

Chen, D., and Mahadevan, S. (2007). "Chloride-induced reinforcement corrosion and concrete cracking simulation." Cement and Concrete Composite, 30:227-238.

Colotti, V., and Spadea, G. (2004). "An analytical model for crack control in reinforced concrete elements under combined forces." Cement and Concrete Composite, 27(4):503-514.

Coronelli, D. (2002). "Corrosion cracking and bond strength modeling for corroded bars in reinforced concrete.” ACI Structural Journal, 99(3):267-276.

Glass, G. K. (1995). "An assessment of the coulostatic method applied to the corrosion of steel in concrete." Corrosion Science, 37(4):597-605.

Gonzalez, J. A., Cobo, A., Gonzalez, M. N., and Feliu, S. (2001). "On-site determination of corrosion rate in reinforced concrete structures by use of galvanostatic pulses." Corrosion Science, 43:611-625.

Granju, J. L., and Balouch, S. (2005). "Corrosion of steel fibre reinforced concrete from the cracks." Cement and Concrete Research, 35(3):572-577.

Kobayashi, K., Iizuka, T., Kurachi, H., and Rokugo, K. (2010). "Corrosion protection of high performance fiber reinforced cement composites as a repair material." Cement and Concrete Research, 32:411-420.

Kojima, Y., Dung, L. A., Rokugo, K., and Kobayashi, K. (2014). "Chloride proofing and rebar corrosion proofing performances of SHCC having cracks." Proc., $3^{\text {rd }}$ International RILEM conference on SHCC, Delft, Netherland.

Li, V.C., Stang, H. and Krenchel, H. (1993). "Micromechanics of crack bridging in fibre-reinforced concrete." Materials and Structures, 26: 486-494.

Liu, T., and Weyers, R. W. (1998). "Modelling the dynamic corrosion process in chloride contaminated concrete structures." Cement and Concrete Research, 28(3):365-379.

Mohammed, T. U., Otsuki, N., Hisada, M., and Shibat, T. (2001). "Effect of crack width and bar types on corrosion of steel in concrete." Journal of Materials Civil Engineering, 13:194-201. 
Otieno, M. B., Alexander, M. G., and Beushausen, H. D. (2010). "Corrosion in cracked and uncracked concrete influence of crack width, concrete quality and crack reopening." Magazine of Concrete Research, 62(6), 393-404.

Paul, S. C., and van Zijl, G. P. A. G. (2014). "Crack formation and chloride induced corrosion in reinforced strain hardening cement-based composites (R/SHCC)." Journal of Advanced Concrete Technology, 12, 340-351.

Paul, S.C. (2015). The role of cracks and chlorides in corrosion of reinforced strain hardening cementbased composite (R/SHCC). PhD thesis, Stellenbosch University, South Africa. ISBN 978-0-62067523-9. http:// scholar.sun.ac.za

RILEM TC 178-TMC. (2002). "Testing and modelling chloride penetration in concrete, Analysis of water soluble chloride content in concrete." Materials and Structures, 35:586-588.

RILEM TC 178-TMC. (2002). "Testing and modelling chloride penetration in concrete, Analysis of total chloride content in concrete." Materials and Structures, 35:583-585.

Sahmaran, M., Li, V.C., and Andrade, C. (2008). "Corrosion resistance performance of steel-reinforced engineered cementitious composite beams." ACI Materials Journal, 105(3): 243-250.

Vidal, T., Castel, A., and Francois, R. (2004). "Analyzing crack width to predict corrosion in reinforced concrete." Cement and Concrete Research, 34(1):165-174.

Wittmann, F. H., Wang, P., Zhang, P., Tie-Jun, Z., and Betzung, F. (2011). "Capillary absorption and chloride penetration in neat and water repellent SHCC under imposed strain." Proc., 2nd International Conference on Strain Hardening Cementitious Composites, Brazil, 165-172. 